\title{
Persistent occurrence of floating Ulva green tide in Hiroshima Bay, Japan: seasonal succession and growth patterns of Ulva pertusa and Ulva spp. (Chlorophyta, Ulvales)
}

\author{
Goro Yoshida • Masayuki Uchimura • \\ Masanori Hiraoka
}

Received: 30 August 2014/Revised: 17 April 2015/Accepted: 17 April 2015/Published online: 29 April 2015

(C) The Author(s) 2015. This article is published with open access at Springerlink.com

\begin{abstract}
Since the late 1980's, a persistent green tide of floating Ulva without any clear seasonal fluctuation has occurred in Hiroshima Bay, Seto Inland Sea, Japan. We hypothesized that the persistence is due to the co-existence of Ulva species with different seasonal growth patterns, and monitored the seasonal composition and growth characteristics of the constituent Ulva within the green tide. Two morphological types of Ulva were identified, and one type, $U$. pertusa, was almost the sole constituent during winter and spring. The other type Ulva spp., which has marginal microscopic serrations on the thallus, was dominant during summer and autumn. Both Ulva showed the highest relative growth rate in early autumn, but growth of Ulva spp. was faster in summer than that of $U$. pertusa and inhibited in winter. $U$.
\end{abstract}

Handling editor: Pierluigi Viaroli

G. Yoshida $(\bowtie)$

National Research Institute of Fisheries and Environment of Inland Sea, Fisheries Research Agency, 2-17-5

Maruishi, Hatsukaichi, Hiroshima 739-0452, Japan

e-mail: gorogoro@affrc.go.jp

M. Uchimura

Research Institute on Subtropical Ecosystems, IDEA

Consultants, Inc., 252 Yaga, Nago, Okinawa 905-1631, Japan

M. Hiraoka

Usa Marine Biological Institute, Kochi University, 194

Inoshiri, Usa, Tosa, Kochi 781-1164, Japan pertusa had more eurythermal characteristics in which the growth rate remained relatively high in winter. Water temperature was the most correlated environmental variable for the seasonal growth of both Ulva types rather than light or nutrients, but more influential on Ulva spp. Recent increasing trend of ambient seawater temperature is considered to be favorable for the growth of both Ulva types and a causative factor of the green tide.

Keywords Green tide $\cdot$ Growth $\cdot$ Seasonal succession - Ulva . Water temperature

\section{Introduction}

During the last few decades, huge green macroalgal blooms termed 'green tides' have been occurring in various coastal areas commonly affected by eutrophication (e.g., Pregnall \& Rudy, 1985; Lavery et al., 1991; Geertz-Hansen et al., 1993; Ménesguen \& Piriou, 1995; Fletcher, 1996; Hernández et al., 1997; Sfriso \& Marcomini, 1997; De Casabianca \& Posada, 1998; Leliaert et al., 2009). Algal taxa causing green tides, such as Ulva, Chaetomorpha, and Cladophora, can exhibit rapid vegetative growth under favorable conditions and in the floating (free-living) form. These characteristics can induce extraordinary increases in abundance and biomass accumulation of these algae along shorelines especially in enclosed sea areas, 
bringing serious consequences to coastal ecosystems (Den Hartog, 1994; Everett, 1994; Isaksson et al., 1994; Viaroli et al. 1996a; Valiela et al., 1997; Sugimoto et al., 2007).

In Japan, green tides have been reported to occur since the 1970's and species of the genus Ulva are the most common constituents (Uno et al., 1983; Arasaki, 1984; Ohno, 1999). It has often been difficult to determine the species forming Ulva green tides correctly because of the lack of morphological features to use as keys for species identification of the genus Ulva due to its simple morphology (Ohno, 1999). However, recent developments in species discrimination techniques using DNA markers have enabled determination of the broad diversity of Ulva species forming green tides (Hiraoka et al., 2002, 2004b; Shimada et al., 2003; Kawai et al., 2007). Furthermore, green tides are often constituted of several dominant species with different eco-physiological characteristics (Fong et al., 1996; Pihl et al., 1996, 1999; Hernández et al., 1997; Nelson et al., 2003). Such green tides are considered to exhibit different ecological characteristics and impacts, i.e., different seasonal occurrences compared with green tides formed of a single species.

Hiroshima Bay is located in the western part of the Seto Inland Sea, the largest semi-enclosed sea area in Japan. In the innermost area of the bay, a continuous green tide by Ulva has been a significant environmental problem since the late 1980's (Uchimura et al., 2004). Mass stranding of floating Ulva thalli on the beaches and tidal flats decreases the esthetic value of Miyajima Is., which is a famous Japanese sightseeing spot in the bay. Accumulation of Ulva thalli on the tidal flats also inhibits growth of Manila clam, Ruditapes philippinarum Adams et Reeve, which is an important local fisheries resource. The economic cost of the manual removal and disposal of the stranded Ulva thalli has also been a concern to local governments and communities (Uchimura et al., 2004).

One of the characteristics of the green tide in Hiroshima Bay is its persistence throughout the year, which means its occurrence without any clear seasonal fluctuation. As a result, the negative effects on the ecosystem and on the local community also continue the whole around the year (Uchimura et al., 2004). The unclear seasonality of the green tide occurrence in Hiroshima Bay could be attributable to it being composed of several species with different ecophysiological traits and seasonal growth patterns.

In this study, floating Ulva in the green tidal biomass in Hiroshima Bay was classified into two morphological types and their seasonal frequency was monitored for two years. As a result, a clear seasonal succession was observed between them. Seasonal growth was also monitored for the two Ulva types using a cage-culture method under natural conditions. Environmental variables were surveyed during the culture, and multiple regression analysis was carried out to examine which environmental variable(s) mostly influence the growth of the two types of Ulva. The results enable a greater understanding of the mechanism underlying the seasonal dominance pattern of the two Ulva types and annual persistence of the green tide in Hiroshima Bay.

\section{Materials and methods}

Identification of different Ulva types and frequency monitoring in the green tide of Hiroshima Bay

From the preliminary observation, floating Ulva in Hiroshima Bay was classified into two types based on their distinct morphological characteristics (Hiraoka et al., 2002). One type was characterized by its entire, smooth margin of the thallus, a cell shape with rounded corners and uneven distribution of chloroplasts in the cell. This type was identified as Ulva pertusa Kjellman, which is the most common species both in the macroalgal vegetation in rocky shores and green tides in Japan (Arasaki, 1984; Ohno, 1999; Hiraoka et al., 2004a). Identification was also ascertained by a cross examination with the benthicattached type of $U$. pertusa (Hiraoka et al., 2002, 2004a), and also by molecular phylogenetic analyses using the nuclear-encoded internal transcribed spacer (ITS) and the plastid-encoded large subunit of ribulose-1,5-bisphosphate carboxylase/oxgenase (rbcL) gene sequences (Shimada et al., 2003). The other type was characterized by a thallus margin with microscopic serrations (tooth-like protuberances), polygonal-shaped cells with a comparatively even distribution of organelles. Pyrenoids were observed more easily in this Ulva type than in U. pertusa. Based on molecular analyses, Hiraoka et al. (2002) and 
Shimada et al. (2003) reported that there were at least three species of floating Ulva with marginal serrations on the thallus in Hiroshima Bay, that is, Ulva armoricana P. Dion, B. de Rivers \& G. Coat, $U$. fasciata Delile and an unknown species which is phylogenetically close to $U$. reticulata Forsskål (Hiraoka et al., 2002; Shimada et al., 2003). As these species described above are similar morphologically, it was very difficult to ensure the materials we sampled and cultured were mono-specific. Therefore, we refer to this type of Ulva which has marginal serrations as Ulva spp.

Floating Ulva thalli for the analysis of frequency in the green tide were sampled on a tidal flat in Ajina, Hatsukaichi City, Hiroshima Prefecture (Fig. 1).On the tidal flat, the accumulation of floating Ulva thalli at a high level $\left(2-3 \mathrm{~kg} \mathrm{w} \mathrm{w} \mathrm{m}^{-2}\right)$ is observed throughout the year, though total Ulva biomass in this area including the subtidal zone peaks in spring as the distribution of Ulva thalli spreads deeper during winter and spring (Uchimura et al., 2004). Sampling was done around the Mean Low Water (M.L.W.)

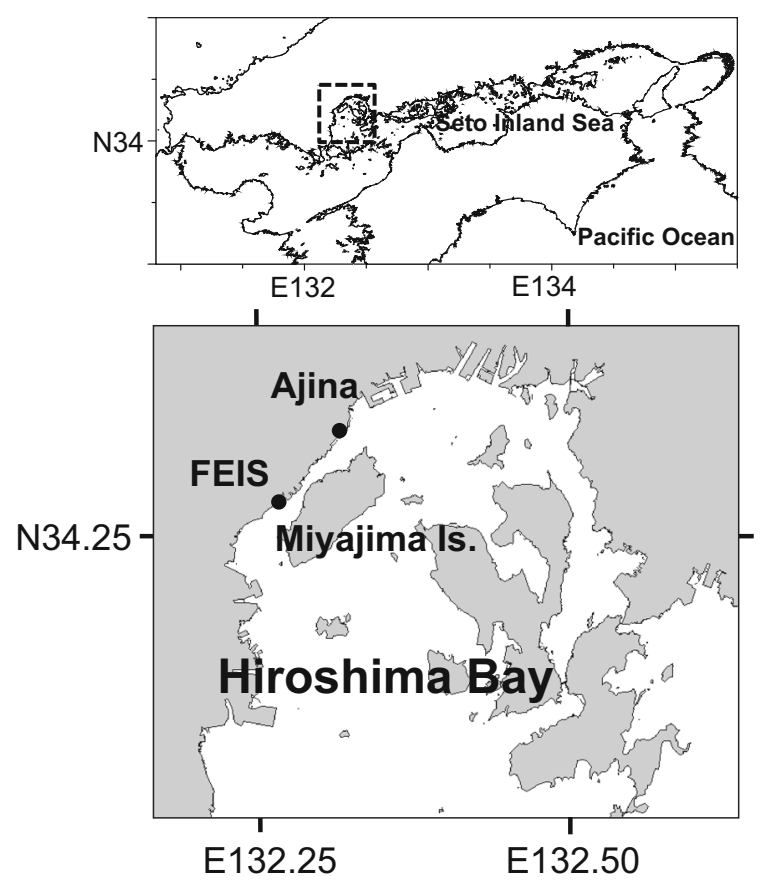

Fig. 1 Location of the sampling site of floating Ulva for monitoring of Ulva type composition in the green tide (Ajina) and the site where cage culture for the two Ulva types was conducted (FEIS; National Research Institute of Fisheries and Environment of Inland Sea) in Hiroshima Bay depth during ebb tides. Between 119 and 170 specimens of Ulva thalli were haphazardly sampled and each was separately wrapped in a paper towel. In the laboratory, each thallus was microscopically observed and classified into the two types according to the morphological characteristics described above. This sampling was conducted 12 times at irregular intervals of 1-3 months from February 2000 to March 2002.

Cage culture and growth estimation of floating Ulva thalli

In this study, a series of cultures was conducted once or twice a month from September 2000 to November 2001 to evaluate the seasonal growth of the two floating Ulva types. The duration of each culture was between 4 and 8 days, and 16 trials of the culture in total were performed.

For all cultures, thalli newly sampled at Ajina at the M.L.W. site described above were used. Ulva thalli were haphazardly collected in a 201 bucket, and in the laboratory, each thallus was classified into the two morphological types. For each type, healthy thalli without any splits, breaks and sections missing, and which were ca. $6 \mathrm{~g}$ in wet weight were chosen for culture materials. This was because the mean weight of floating Ulva thalli on Ajina tidal flat was $6.6 \mathrm{~g}$ ( \pm 4.1 SD) in a preliminary study in September 2000 (Yoshida, unpublished). Therefore, thallus with a weight of ca. $6 \mathrm{~g}$ was assumed to be representative of thalli forming the green tide. The thallus area of $6 \mathrm{~g}$ in weight was approximately $700 \mathrm{~cm}^{2}$ for $U$. pertusa and $900 \mathrm{~cm}^{2}$ for Ulva spp. We could not find any Ulva spp. in February, March, and April 2001 in the samples collected in the bucket on the tidal flat. So during these months, only $U$. pertusa was cultured in the cages.

Transparent cylindrical PVC cages, $13 \mathrm{~cm}$ in diameter and $25 \mathrm{~cm}$ in length, were used for culture. Both ends of the cages were closed with 8-mm mesh net to keep the Ulva thalli inside. Numerous small holes ( $8 \mathrm{~mm}$ in diameter) were also made in the cylindrical cages to enable water exchange. Only one Ulva thallus was put in a cage and six cages were assigned for each Ulva type.

Cages with Ulva thalli inside were suspended just beneath the sea surface from the rope stretched between frames of the culture system of the National Institute of Fisheries and Environment of Inland Sea (FEIS, Fig. 1). The weight of each thallus was 
measured in the laboratory just before and after each culture, after the surface of the thallus was wiped by paper towels to remove excess water. Relative growth rate (RGR) was calculated as follows:

$$
\begin{aligned}
& \operatorname{RGR}\left(\text { days }^{-1}\right)=\{\ln (\text { final weight }) \\
& -\ln (\text { initial weight })\} / \text { days of culture. }
\end{aligned}
$$

\section{Environmental parameters}

Water temperature was recorded every $30 \mathrm{~min}$ by a data-logger Optic StowAway Temp (Onset Computer Corporation) suspended at the same depth as the vessels. Salinity was recorded at 9:00 every day by DataSonde3 (Hydrolab Corporation) set on the pontoon of FEIS. Daily irradiance was surveyed every 10 min by a LI-193 spherical quantum sensor (Li-Cor) set on the roof of FEIS and recorded in a data-logger LI-1000 (Li-Cor). For these environmental parameters, mean values during each culture was calculated. Surface seawater for nutrient analysis was sampled in every culture trial, usually at the start or during the first half of each culture. Sampled seawater was filtered through GF/F glass-fiber filters, and DIN (dissolved inorganic nitrogen; $\mathrm{NO}_{3}$ $\mathrm{N}+\mathrm{NO}_{2}-\mathrm{N}+\mathrm{NH}_{4}-\mathrm{N}$ ) and DIP (dissolved inorganic phosphorus; $\mathrm{PO}_{4}-\mathrm{P}$ ) concentrations were measured using the continuous flow analytical system Model Traacs-2000 (Bran + Luebbe).

Data analysis

RGR data were examined by a two-way ANOVA with Ulva types and seasons (trials of culture) treated as fixed factors, to detect a significant Ulva type $\times$ season interaction. The post hoc Bonferroni test was conducted to elucidate relationships among RGR data. Normality and homogeneity of variance were checked by ShapiroWilk test and Levene's test, respectively. All these analyses and tests were carried out using SPSS 20.0 Statistic (IBM). As there was a possibility that several species were contained in our Ulva spp. materials, coefficient of variation in RGR was compared between $U$. pertusa and Ulva spp., to estimate the heterogeneity in growth rate among Ulva spp. materials.

Multiple regression analysis was conducted to determine which environmental variable(s), i.e., water temperature, salinity, daily irradiance, and DIN and DIP concentrations, showed the highest correlation with the growth rate of Ulva. Multicollinearity among environmental variables was checked in Variance Inflation Factor (VIF) values shown in the results of SPSS, assuming variables with the VIF values larger than 10 should be abandoned as multicollinearity could occur and affect the result (Hair et al., 1995). In our results, VIF values for all environmental variables were below 10 and indicated that substantial effects of multicollinearity did not occur. Standardized partial regression coefficient was taken to estimate the degree of influence of each explanatory variable on RGR. This analysis was also carried out using SPSS.

\section{Results}

Seasonal changes in Ulva constituents in the green tide

Seasonal changes in frequency of the two Ulva types, $U$. pertusa and Ulva spp. in the green tide at the Ajina tidal flat in Hiroshima Bay are shown in Fig. 2. In winter and spring of 2000, U. pertusa accounted for $98-100 \%$ in the frequency. Ulva spp. appeared in summer and became dominant in autumn, in which the frequency of Ulva spp. was 82\% in October 2000. Ulva spp. began to decrease in December and its frequency became quite low in winter and spring of 2001, when $U$. pertusa became dominant again and

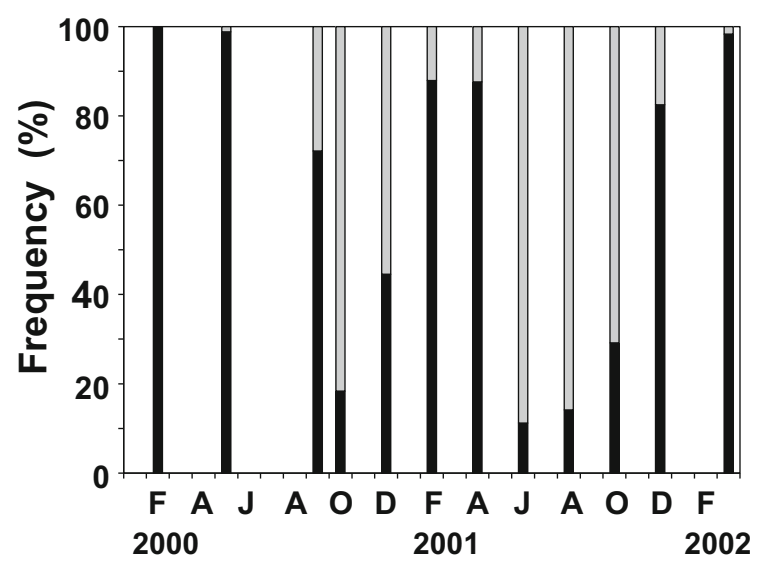

Fig. 2 Seasonal change in frequency of the two Ulva types, $U$. pertusa (filled square) and Ulva spp. (shaded square) in the green tide of Ajina tidal flat, Hiroshima Bay 
accounted for approximately $90 \%$. A similar seasonal change in frequency occurred in 2001-2002; however, Ulva spp. had already been dominant (89\%) in June 2001.

Environmental variables during the cultures

Fluctuations in water temperature, salinity, and mean daily irradiance during cultures are shown in Fig. 3. Water temperature changed seasonally between $10.5^{\circ} \mathrm{C}$ recorded in mid February 2001 and $25.5^{\circ} \mathrm{C}$ in mid September 2000. Salinity fluctuated among 20.4-33.1\%o. During autumn to spring, salinity remained at a relatively higher level $(>31.0 \%$ ), though it dropped to $20-21 \%$ in the rainy (June) and typhoon

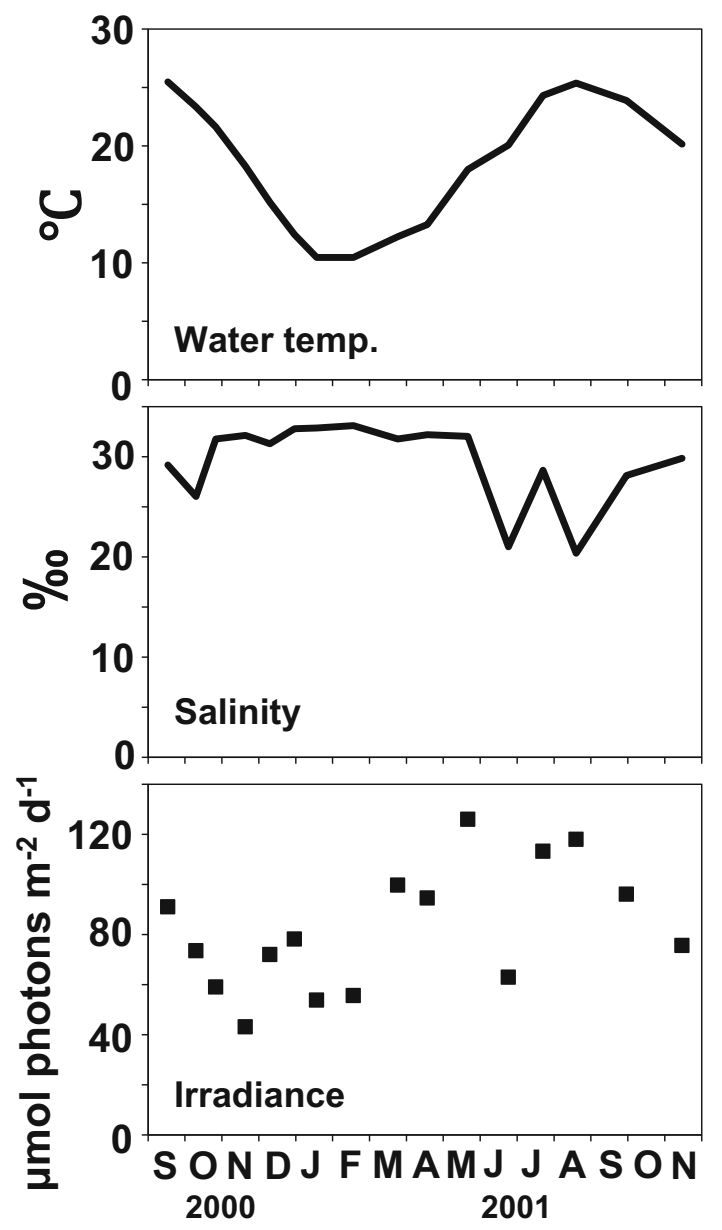

Fig. 3 Seasonal changes in mean water temperature, salinity and irradiance during the culture study of the two Ulva types in the cages
(August) seasons. Mean daily irradiance also changed seasonally and was high in May and summer (JulyAugust).

Seasonal variations in DIN and DIP concentrations are shown in Fig. 4. DIN concentration was higher (ca. $10 \mu \mathrm{M})$ during autumn and winter. It decreased to 1-3 $\mu \mathrm{M}$ in spring to summer (April-August.) except for in June 2001 when the runoff-derived nitrogen load increased. DIN concentration increased again after September 2001. In DIN, nitrate-N contributed 40.6-85.7\% (mean 63.5\%), whereas ammonium-N contributed 10.0-48.9\% (mean 29.1\%) (data not shown). DIP exhibited a similar seasonal fluctuation with DIN, but it began to decline soon after a short peak in early autumn (September- October). Increase in the rainy month (June) as in the case of DIN was not observed in DIP.

Seasonal variations in RGR of U. pertusa and Ulva spp

Ranges of seasonal fluctuations in the relative growth rate (RGR) were $0.11-0.22$ days $^{-1}$ for $U$. pertusa and 0.04-0.24 days ${ }^{-1}$ for Ulva spp. (Figure 5). RGRs of

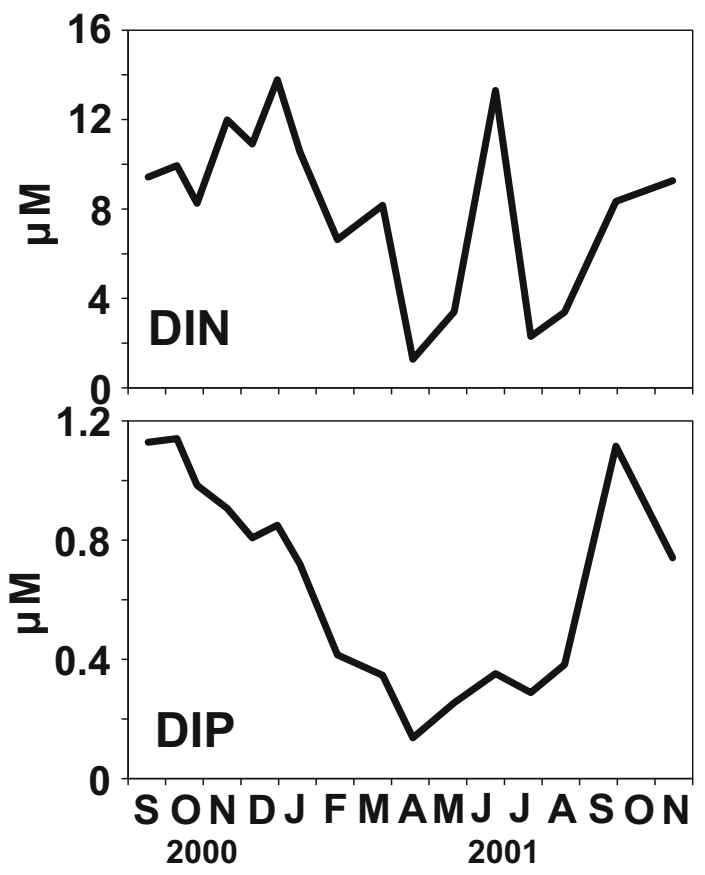

Fig. 4 Seasonal changes in DIN and DIP concentrations in seawater during the culture study of the two Ulva types in the cages 


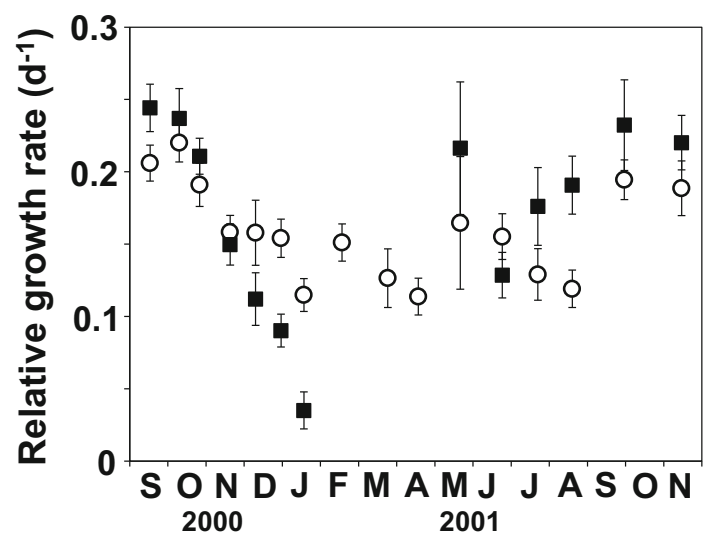

Fig. 5 Seasonal changes in the relative growth rate (RGR) with $\mathrm{SD}$ of $U$. pertusa (open circle) and Ulva spp. (filled square)

both Ulva types were the highest in autumn (in early October 2000 for U. pertusa, and in September 2000 for Ulva spp.) and progressively decreased until winter. However, RGRs of $U$. pertusa remained at a relatively higher level $\left(0.12-0.15\right.$ days $\left.^{-1}\right)$ in January to March whereas RGRs of Ulva spp. decreased rapidly to the lowest value $\left(0.04\right.$ days $\left.^{-1}\right)$ just before Ulva spp. became scarce in the green tide in January. After its reappearance in May, Ulva spp. exhibited higher RGRs than RGRs of $U$. pertusa during summer except for in June. The differences in RGRs were significant between the Ulva types (two-way ANOVA, $F=4.85, \mathrm{df}=1, P<0.05$ ) and among seasons (twoway ANOVA, $F=48.44$, df $=15, P<0.01$ ), and a significant Ulva type $\times$ season interaction was detected (two-way ANOVA, $F=15.24$, df $=12$, $P<0.01)$ indicating that the seasonal growth patterns of the two Ulva types were different from each other. RGRs of the two Ulva types in every pair of the identical culture trial were significantly different except the RGR pairs in October and November 2000 (Bonferroni test, $P<0.05$ ).

Coefficient of variation (CV) in RGR ranged 6.0-27.9\% in U. pertusa and 5.9-36.4\% in Ulva spp. (Figure 6). CV in RGR of Ulva spp. abruptly rose in January just before Ulva spp. disappeared from the green tide community at the sampling site. The values of the two types in May were also high, when Ulva spp. reappeared. Excluding those values, CV in RGR of the two types fluctuated in similar ranges (6.0-16.0\% in U. pertusa and $5.9-16.2 \%$ in Ulva spp.).

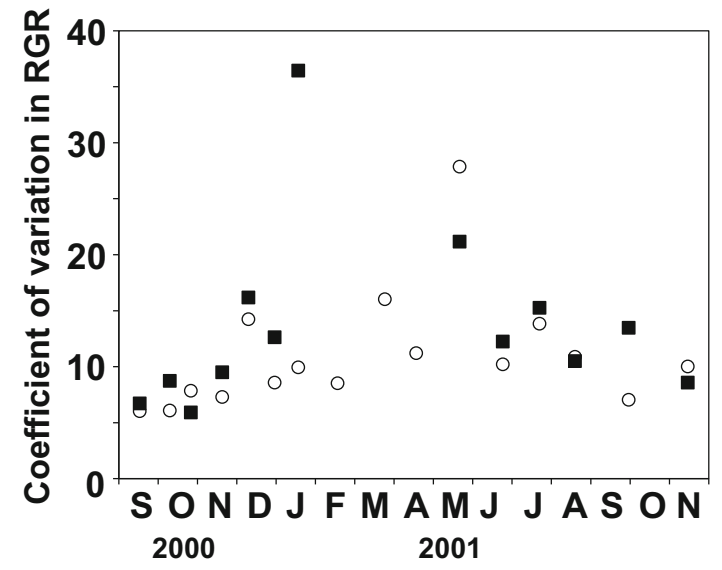

Fig. 6 Seasonal changes in coefficient of variation (CV) in RGR of $U$. pertusa (open circle) and Ulva spp. (filled square)

Table 1 Standardized partial regression coefficients and ANOVA test results on the multiple regression analysis relating RGR of the two Ulva types and environmental variables

\begin{tabular}{lcc}
\hline Environmental variables & \multicolumn{2}{l}{ RGR } \\
\cline { 2 - 3 } & Ulva pertusa & Ulva $\mathrm{spp}$. \\
\hline Water temperature & $0.485^{* *}$ & $0.952^{* * * *}$ \\
Salinity & 0.218 & $0.335^{* *}$ \\
Irradiance & 0.012 & $0.274^{*}$ \\
DIN & 0.167 & 0.17 \\
DIP & $0.405^{* *}$ & 0.113 \\
$F$ & $20.44^{* *}$ & $41.58^{* * *}$ \\
$R^{2}$ & 0.51 & 0.73 \\
\hline
\end{tabular}

Significant partial regression coefficients and $F$ values are marked: $* P<0.05, * * P<0.01, * * * P<0.001$

Relationship between RGR and environmental variables

Results of the multiple regression analysis are shown in Table 1. For U. pertusa growth, water temperature, and DIP were chosen as the significant correlated variables. Though the standardized partial regression coefficient of water temperature was the largest (0.485), the coefficient of DIP was 0.405 and the difference between the two values was small. In the results for Ulva spp., water temperature, salinity, and irradiance were significantly correlated with RGR, but the influence of the water temperature on the RGR (standardized partial regression coefficient $=0.952$ ) was far larger than that of salinity (0.335) and irradiance (0.274). 
From the values of partial regression coefficient of water temperature on RGRs of the two Ulva types, it is considered that temperature is more influential on Ulva spp. (Table 1). Partial regression plots of the RGR of U. pertusa and Ulva spp. to mean water temperature during each cage culture (Fig. 7) also indicates that growth of Ulva spp. was more sensitive to lower water temperature levels than that of $U$. pertusa.

\section{Discussion}

Seasonal changes in dominant species or species composition have often been observed in green tides worldwide (Pregnall \& Rudy, 1985; Lavery et al., 1991; Rivers \& Peckol, 1995; Fong et al., 1996; Pihl et al., 1996). In some cases, environmental shifts or catastrophic events caused absolute replacement of dominant species (Lavery et al., 1991). Green macroalgae causing green tides have common opportunistic characteristics with high growth rates under favorable conditions. However, there are also

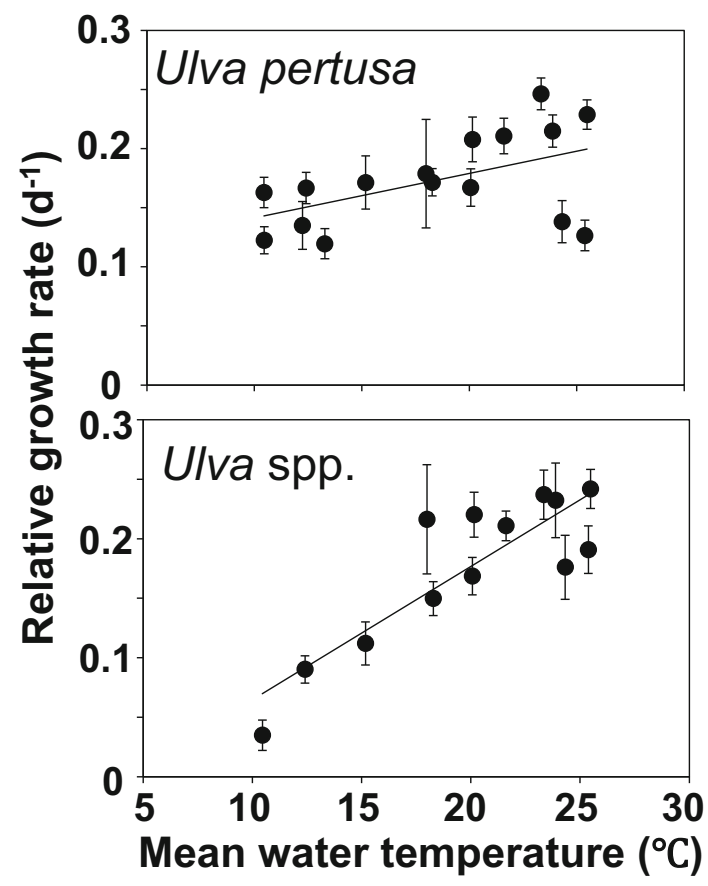

Fig. 7 Partial regression plots (with SD) of the relative growth rate of $U$. pertusa and Ulva spp. to mean water temperature during each cage culture differences in some eco-physiological traits among species, e.g., abilities in nutrient uptake and stock, tolerance to high temperature or anaerobic conditions. These differences among species can lead to seasonal or incidental successions in green tides (Lavery et al., 1991; Rivers \& Peckol, 1995).

In this study, a clear seasonal succession between $U$. pertusa and Ulva spp. was observed in the green tide on the Ajina tidal flat in Hiroshima Bay (Fig. 2), and it was shown that this succession was clearly attributable to the differences in seasonal growth characteristics of the two Ulva types.

Seasonal changes in temperature, light in the water column, and nutrients (especially, nitrogen) are known as important variables regulating Ulva growth in the green tide (Ménesguen \& Piriou, 1995; Sfriso, 1995; Riccardi \& Solidoro, 1996; Viaroli et al., 1996b; Yamasaki et al., 1996; Malta \& Verschuure, 1997; De Casabianca \& Posada, 1998; Naldi \& Viaroli, 2002). In our study, water temperature was the most correlated variable among the other environmental variables with the RGRs for both types of Ulva. Growth of Ulva spp. was more dependent on temperature, and it was inhibited under the lowest water temperature of the year. On the contrary, the result indicated that $U$. pertusa has a more eurythermal growth characteristic than Ulva spp.(Figure 7).

Although growth in summer and autumn was faster in Ulva spp. than in U. pertusa, the RGRs of $U$. pertusa remained 0.1 days $^{-1}$ (Fig. 5). During these seasons, however, $U$. pertusa accounted for only a small portion in the green tidal biomass (Fig. 2). This indicates that Ulva spp. has competitive advantages over $U$. pertusa in the dense accumulation of floating thalli $\left(2-3 \mathrm{~kg} \mathrm{w} \mathrm{w} \mathrm{m}^{-2}\right)$ in these seasons (Uchimura et al. 2004). It was reported that the high water temperature in summer induces formation and release of zoospores in the attached type $U$. pertusa (Uchimura et al., 2004), and this causes growth reduction. However, we did not recognize maturation, at least in our floating $U$. pertusa material and they continued vegetative growth during the summer. In other reports, it was also mentioned that floating type of Ulva commonly has infertile characteristics and seldom form zoospores (Migita, 1985; Hiraoka et al., 2004a). Therefore, the superiority of Ulva spp. over U. pertusa in the green tide during summer and autumn is considered to be attributable to their differences in eco-physiological potentials. 
Nutrient uptake ability is a significant factor in the competition among co-occurring species in the green tide. In the Ulva green tide that has recently occurred in the Yellow Sea, China, the dominant species Ulva prolifera $\mathrm{O}$. F. Müller was superior in nitrogen uptake and stock ability compared to co-occurring Ulva linza Linnaeus (Luo et al., 2012). In our results, DIP was selected as a correlated variable on the RGR of $U$. pertusa cultured in the cages. In many previous reports in temperate regions, nitrogen has been indicated to be more important than phosphorus, which limits algal growth and production (Lavery \& McComb, 1991; Ménesguen \& Piriou, 1995; Rivers \& Peckol, 1995; Fong et al., 1996; Viaroli et al., 1996b; Malta \& Verschuure, 1997; Sfriso \& Marcomini, 1997; Naldi \& Viaroli, 2002). For now, we are not sure if summer growth of $U$. pertusa is phosphorus-limited in Hiroshima Bay, but it is possible that growth of $U$. pertusa is influenced more seriously by nutrient shortage in summer than Ulva spp. Studies on nutritional eco-physiology of different Ulva species is also essential to understand the mechanism of seasonal succession in the green tide of Hiroshima Bay.

As mentioned in the Materials and Methods, our materials of Ulva spp. for culture could be constituted of multiple-species, and at least three candidate species exist. However, the coefficients of variance in RGRs of Ulva spp. showed similar seasonal fluctuations and ranges with those of $U$. pertusa over most of the year. Therefore, growth response of Ulva spp. was as homogenous as that of the monospecific $U$. pertusa. This indicates that Ulva spp. might be constituted mostly of a single species, or that, even though Ulva spp. was constituted of multiple species, they had a similar seasonal growth pattern.

Recent research has shown that another Ulva species other than $U$. pertusa contributes to green tides which occur along the south-western Japanese coast, e.g., Tosa Bay in Kochi Prefecture and Hakata Bay in Fukuoka Prefecture (Hiraoka et al., 2004a, b). This species has a thallus margin with microscopic serrations, and in 2004, it was reported as a new species Ulva ohnoi M. Hiraoka \& S. Shimada (Hiraoka et al., 2004b). U. ohnoi forms green tides in summer and autumn and shows poor growth around $10^{\circ} \mathrm{C}$ which is close to the winter temperature in the western Japanese coastal waters. As this species distributes along the coast facing to warm currents
(Kuroshio and Tsushima), it is supposed U. ohnoi has a subtropical or tropical origin (Hiraoka et al. 2004b).

Among the three candidate species of Ulva spp. in our study, $U$. armoricana was described as a new species in France (Dion et al., 1998) and is considered to have been introduced to Japan (Shimada et al., 2003). European species of Ulva have a relatively lower optimal temperature $\left(10-20^{\circ} \mathrm{C}\right)$ for growth and photosynthesis than Japanese species $\left(20-30^{\circ} \mathrm{C}\right)$ (Murase et al., 1993; De Casabianca \& Posada, 1998; Taylor et al., 2001), and exhibit the highest growth or peak in biomass in spring to early summer (Sfriso, 1995; Viaroli et al., 1996b; De Casabianca \& Posada, 1998; Naldi \& Viaroli, 2002). These ecophysiological and seasonal characteristics do not correspond with those of Ulva spp. in our study. The second candidate $U$. fasciata is a warm-temperate to subtropical species (Yoshida, 1998) and Arasaki (1984) indicated that this species had extended its distribution into the Seto Inland Sea in the 1970's. And for the third candidate, which is unknown but closely related species to $U$. reticulata (Hiraoka et al., 2002), we consider it is possibly $U$. ohnoi and the main constituent of Ulva spp. in our study. Although they are different species, $U$. reticulata and $U$. ohnoi are closely related taxa to form a monophyletic clade in the phylogenic trees in a molecular analysis, as with other species with marginal serrations (Hiraoka et al., 2004b). In addition, the seasonal appearance pattern of Ulva spp. in our study is quite similar with that of $U$. ohnoi in Tosa Bay, in which the biomass increases from summer to autumn (Ohno, 1988). Furthermore, seasonal succession of dominance between $U$. pertusa and $U$. ohnoi was also reported in Mikawa Bay (Kawai et al., 2007) and Tokyo Bay (Yabe et al., 2009) in central Japan. All these former reports seem to support our hypothesis that $U$. ohnoi was the main constituent of Ulva spp., though U. fasciata was also a possible constituent as Arasaki (1984) indicated. Further studies including genetic analyses are necessary for species identification, as well as examination of the species composition, of Ulva spp.

Water temperature in the Seto Inland Sea has been rising over the past 30 years and the annual mean of water temperature during 1966-2002 has increased by $0.8^{\circ} \mathrm{C}$ (Yamamoto, 2003). The increase trend of water temperature began in the late 1980's and was remarkable in the 1990's. Although mass propagation of Ulva was first reported in the 1970's in Yamaguchi Bay in 
the western Seto Inland Sea (Uno et al., 1983), serious effects by green tide in Hiroshima Bay has been recognized since the late 1980's (Uchimura et al., 2004). This timing of green tide occurrence in Hiroshima Bay was coincident with the duration of continuous water temperature increase described above.

In 1995, a newly green tide also occurred in Yatsu tidal flat of Tokyo Bay, and this was considered to be due to unintentional introduction of U.ohnoi and its excessive growth. In the case of Tokyo Bay, notable air temperature rise in 1990's, which could have also affected water temperature of the tidal flat, is considered to be the inducible factor of the green tide occurrence rather than eutrophication (Yabe et al., 2009). The situation is quite similar with that of the Seto Inland Sea, because nutrient loading in the Seto Inland Sea has been legislatively controlled and decreasing after serious eutrophication in the 1960's and early 1970's (Seiki et al., 1998).

Trend of water temperature increase in the Seto Inland Sea is significant in winter. Although increase in summer does not show a significant trend, the number of days in a year with daily mean water temperature exceeding $25^{\circ} \mathrm{C}$ has been increasing since 1995 (Yamamoto, 2003). The trend of water temperature increase could have allowed the invasion of alien Ulva species like $U$. ohnoi, and also could be advantageous for the growth of native $U$. pertusa especially in winter when competition with alien Ulva species could be avoided.

In conclusion, the green tide in Hiroshima Bay is composed of two different Ulva types with different patterns of seasonal growth, and this leads to the persistence of the green tide throughout the year. Water temperature increase is considered to be favorable to both Ulva types and could have induced the occurrence of the green tide in the past. Further research is needed to monitor geographic expansion of green tides, because coastal water temperature in Japan is forecast to continue to increase in the future due to the effects of global warming.

Acknowledgments We express our thanks to Dr. Kenji Tarutani, Fisheries Research Agency, for offering his monitoring data of salinity. We are also grateful to Dr. T. Terawaki, Fisheries Research Agency, for his useful suggestions, and to Mrs. M. Okushin, Mrs. K.Nakaso for their assistance on our study.
Open Access This article is distributed under the terms of the Creative Commons Attribution 4.0 International License (http:// creativecommons.org/licenses/by/4.0/), which permits unrestricted use, distribution, and reproduction in any medium, provided you give appropriate credit to the original author(s) and the source, provide a link to the Creative Commons license, and indicate if changes were made.

\section{References}

Arasaki, S., 1984. A new aspect of Ulva vegetation along the Japanese coast. Hydrobiologia 116(117): 229-232.

De Casabianca, M.-L. \& F. Posada, 1998. Effect of environmental parameters on the growth of Ulva rigida (Thau Lagoon, France). Botanica Marina 41: 157-165.

Den Hartog, C., 1994. Suffocation of a littoral Zostera bed by Enteromorpha radiata. Aquatic Botany 47: 21-28.

Dion, P., B. De Reviers \& G. Coat, 1998. Ulva armoricana sp. nov. (Ulvales, Chlorophyta) from the coasts of Brittany (France). I Morphological identification. European Journal of Phycology 33: 73-80.

Everett, R. A., 1994. Macroalgae in marine soft-sediment communities: effects on benthic faunal assemblages. Journal of Experimental Marine Biology and Ecology 175: 253-274.

Fletcher, R. T., 1996. The occurrence of 'green tide'. In Schramm, W. \& P. H. Nienhuis (eds), Marine Benthic Vegetation-Recent Changes and the Effects of Eutrophication. Springer, Berlin: 7-43.

Fong, P., K. E. Boyer, J. S. Desmond \& J. B. Zedler, 1996. Salinity stress, nitrogen competition, and facilitation: what controls seasonal succession of two opportunistic green macroalgae? Journal of Experimental Marine Biology and Ecology 206: 203-221.

Geertz-Hansen, O., K. Sand-Jensen, D. F. Hansen \& A. Chrstiansen, 1993. Growth and grazing control of abundance of the marine macroalga, Ulva lactuca L. in a eutrophic Danish estuary. Aquatic Botany 46: 101-109.

Hair, J. F., R. E. Anderson, R. L. Tatham \& W. C. Black, 1995. Multivariate Data Analysis with Readings, 4th ed. Prentice Hall, Upper Saddle River.

Hernández, I., G. Peralta, J. L. Pérez-Lloréns \& J. J. Vergara, 1997. Biomass and dynamics of growth of Ulva species in Palmones River estuary. Journal of Phycology 33: $764-772$.

Hiraoka, M., S. Shimada \& G. Yoshida, 2002. Green tide. In Hori, T., M. Ohno \& T. Horiguchi (eds), Nijŷ̂-isseiki syotou no sô-gaku no genkyô. Japanese Society of Phycology, Yamagata: 98-101 (in Japanese).

Hiraoka, M., M. Ohno, S. Kawaguchi \& G. Yoshida, 2004a. Crossing test among floating Ulva thalli forming 'green tide' in Japan. Hydrobiologia 512: 239-245.

Hiraoka, M., S. Shimada, M. Uenosono \& M. Masuda, 2004b. A new green-tide-forming alga, Ulva ohnoi Hiraoka et Shimada sp. nov. (Ulvales, Ulvophyceae) from Japan. Phycological Research 51: 17-29.

Isaksson, I., L. Pihl \& J. van Montfrans, 1994. Eutrophicationrelated changes in macrovegetation and foraging of young 
cod (Gadus morhua L.): a mesocosm experiment. Journal of Experimental Marine Biology and Ecology 177: 203-217.

Kawai, H., S. Shimada, T. Hanyuda, T. Suzuki \& Gamagori City Office, 2007. Species diversity and seasonal changes of dominant Ulva species (Ulvales, Ulvophyceae) in Mikawa Bay, Japan, deduced from ITS2 rDNA region sequences. Algae 22: 221-228.

Lavery, P. S. \& A. J. McComb, 1991. The nutrient eco-physiology of Chaetomorpha linum and Ulva rigida in Peel Inlet, western Australia. Botanica Marina 34: 251-260.

Lavery, P. S., R. J. Lukatelich \& A. J. McComb, 1991. Changes in the biomass and species composition of macroalgae in a eutrophic estuary. Estuarine, Coastal and Shelf Science 33: $1-22$.

Leliaert, F., X. Zhang, N. Ye, E. Malta, A. H. Engelen, F. Mineur, H. Verbruggen \& O. De Clerck, 2009. Identify of the Qingdao algal bloom. Phycological Research 57: 147-151.

Luo, M. B., F. Liu \& Z. L. Xu, 2012. Growth and nutrient uptake capacity of two co-occurring species, Ulva prolifera and Ulva linza. Aquatic Botany 100: 18-24.

Malta, E.-J. \& J. M. Verschuure, 1997. Effects of environmental variables on between-year variation of Ulva growth and biomass in a eutrophic brackish lake. Journal of Sea Research 38: 71-84.

Ménesguen, A. \& J.-Y. Piriou, 1995. Nitrogen loadings and macroalgal (Ulva sp.) mass accumulation in Brittany (France). Ophelia 42: 227-237.

Migita, S., 1985. The sterile mutant of Ulva pertusa Kjellman from Omura Bay. Bulletin of the Faculty of Fisheries Nagasaki University 57: 33-37 (in Japanese with English abstract).

Murase, N., M. Maegawa, T. Matsui, M. Ohgai, N. Katayama, M. Saitoh \& Y. Yokohama, 1993. Growth and photosynthesis temperature characteristics of the sterile Ulva pertusa. Nippon Suisan Gakkaishi 60: 625-630 (in Japanese with English abstract).

Naldi, M. \& P. Viaroli, 2002. Nitrate uptake and storage in the seaweed Ulva rigida C. Agardh in relation to nitrate availability and thallus nitrate content in a eutrophic coastal lagoon (Sacca di Goro, Po River Delta, Italy). Journal of Experimental Marine Biology and Ecology 269: 65-83.

Nelson, T. A., A. V. Nelson \& M. Tjoelker, 2003. Seasonal and spatial patterns of "green tides" (ulvoid algal blooms) and related water quality parameters in the coastal waters of Washington State, USA. Botanica Marina 2003: 263-275.

Ohno, M., 1988. Seasonal changes of the growth of green algae, Ulva sp. in Tosa Bay, southern Japan. Marine Fouling 7: 13-17 (in Japanese).

Ohno, M., 1999. Ulva and excessive growth. In Notoya, M. (ed.), The Utilization and Environmental Remediation in Ulva. Seizan-dou, Tokyo: 1-15 (in Japanese).

Pihl, L., G. Magnusson, I. Isaksson \& I. Wallentinus, 1996. Distribution and growth dynamics of ephemeral macroalgae in shallow bays on the Swedish west coast. Journal of Sea Research 35: 169-180.

Pihl, L., A. Svenson, P.-O. Moksnes \& H. Wennhage, 1999. Distribution of green algal mats throughout shallow soft bottoms of the Swedish Skagerrak archipelago in relation to nutrient sources and wave exposure. Journal of Sea Research 41: 281-294.
Pregnall, A. M. \& P. P. Rudy, 1985. Contribution of green macroalgal mats (Enteromorpha spp.) to seasonal production in an estuary. Marine Ecology Progress Series 24: 167-176.

Riccardi, N. \& C. Solidoro, 1996. The influence of environmental variables on Ulva rigida $\mathrm{C}$. Ag. growth and production. Botanica Marina 39: 27-32.

Rivers, J. S. \& P. Peckol, 1995. Summer decline of Ulva lactuca (Chlorophyta) in a eutrophic embayment: Interactive effects of temperature and nitrogen availability? Journal of Phycology 31: 223-228.

Seiki, T., Y. Komai, T. Koyama, O. Nagafuchi, Y. Hino \& K. Murakami, 1998. Shift of the circumstances in effluent pollutant loads and water pollution in the Seto Inland Sea. Journal of Japan Society on Water Environment 21: 780-788 (in Japanese with English Abstract).

Sfriso, A., 1995. Temporal and spatial responses of growth of Ulva rigida $\mathrm{C}$. Ag. to environmental and tissue concentrations of nutrients in the Lagoon of Venice. Botanica Marina 38: 557-573.

Sfriso, A. \& A. Marcomini, 1997. Macrophyte production in a shallow coastal lagoon. Part I: Coupling with chemicophysical parameters and nutrient concentrations in waters. Marine Environmental Research 44: 351-375.

Shimada, S., M. Hiraoka, S. Nabata, M. Iima \& M. Masuda, 2003. Molecular phylogenetic analyses of the Japanese Ulva and Enteromorpha (Ulvales, Ulvophyceae), with special reference to the free-floating Ulva. Phycological Research 51: 99-108.

Sugimoto, K., K. Hiraoka, S. Ohta, Y. Niimura, T. Terawaki \& M. Okada, 2007. Effects of ulvoid (Ulva spp.) accumulation on the structure and function of eelgrass (Zostera marina L.) bed. Marine Pollution Bulletin 54: 1582-1585.

Taylor, R., R. L. Fletcher \& J. A. Raven, 2001. Preliminary studies on the growth of selected 'green tide' algae in laboratory culture: effects of irradiance, temperature, salinity and nutrients on growth rate. Botanica Marina 44: 327-336.

Uchimura, M., G. Yoshida, M. Hiraoka, T. Komatsu, S. Arai \& T. Terawaki, 2004. Ecological studies of green tide, Ulva spp. (Chlorophyta) in Hiroshima Bay, the Seto Inland Sea. The Japanese. Journal of Phycology 52(Supplement): 17-22.

Uno, S., Y. Sakai \& K. Yoshikawa, 1983. Distribution of Ulva pertusa and amount of nitrogen in Yamaguchi Bay ( $S \hat{o}$ rui). Japanese Journal of Phycology 31: 148-155.

Valiela, I., J. McClelland, J. Hauxwell, P. J. Behr, D. Hersh \& K. Foreman, 1997. Macroalgal blooms in shallow estuaries: Controls and eco-physiological and ecosystem consequences. Limnology and Oceanography 42: 1105-1118.

Viaroli, P., M. Bartoli, C. Bondavalli, R. R. Christian, G. Giordani \& M. Naldi, 1996a. Macrophyte communities and their impact on benthic fluxes of oxygen, sulphide and nutrients in shallow eutrophic environments. Hydrobiologia 329: 105-119.

Viaroli, P., M. Naldi, C. Bondavalli \& S. Bencivelli, 1996b. Growth of the seaweed Ulva rigida C. Agardh in relation to biomass densities, internal nutrient pools and external nutrient supply in the Sacca di Goro lagoon (Northern Italy). Hydrobiologia 329: 93-103.

Yabe, T., Y. Ishii, Y. Amano, T. Koga, S. Hayashi, S. Nohara \& H. Tatsumoto, 2009. Green tide formed by free-floating Ulva spp. at Yatsu tidal flat, Japan. Limnology 10: 239-245. 
Yamamoto, M., 2003. The long-term variations in water temperature and salinity in Bisan-Seto, the central Seto Inland Sea. Bulletin of Japanese Society of Fisheries Oceanography 67: 163-167 (in Japanese with English abstract).

Yamasaki, S., M. Matsuda, T. Yamauchi \& H. Hirata, 1996. Effects of light and water temperature on the growth of
Ulva sp. in a fish culture farm. Suisanzoshoku 44: 413-418 (in Japanese with English abstract).

Yoshida, T., 1998. Marine Algae of Japan. Uchida Roukakuho, Tokyo. 